\title{
Online Versus Flipped Classroom: A Comparison of Hands-On Skills Devel- opment in an Introductory Circuits Course
}

\section{Dr. David J. Cheney, University of Florida}

David Cheney is a lecturer at the University of Florida. He instructs courses in circuits, electrical engineering design, and computer architecture. He received his received his $\mathrm{PhD}$, Master of Engineering, and B.S.E.E. in Electrical and Computing Engineering from the University of Florida and has been a co-author on over 25 publications and conference presentations.

His vast engineering experience includes supercomputer CPU design, protective relaying and metrology in the electric utility industry, software application development (database and control), brain-machine interface research, compound semiconductor research, and has extensive experience in system integration.

\section{Dr. Pamela L. Dickrell, University of Florida}

Dr. Pamela Dickrell is the Associate Director of the Institute for Excellence in Engineering Education, in the UF Herbert Wertheim College of Engineering. Her role as Associate Director of the Institute focuses on effective teaching methods and hands-on learning opportunities for undergraduate student engagement and retention. Dr. Dickrell received her B.S., M.S., and Ph.D. in Mechanical Engineering from the University of Florida, specializing in Tribology. Her current research areas include hands-on and makerspace education methods for diverse student retention and inclusion.

\section{Dr. Lilianny Virguez, University of Florida}

Lilianny Virguez is a Lecturer at the Institute for Excellence in Engineering Education at University of Florida. She holds a Masters' degree in Management Systems Engineering and a Ph.D. in Engineering Education from Virginia Tech. She has work experience in engineering and has taught engineering courses at the first-year level.Her research interests include motivation to succeed in engineering with a focus on first-year students. 


\section{On-line Versus Flipped Classroom: A Comparison of Hands-On}

Skills Development in an Introductory Circuits Course 


\section{Introduction}

Universities have been examining a variety of alternatives to the traditional teaching method of lecturing to students, many of which utilize technology to enhance or expand the traditional lecture experience[1][2]. For classes with large enrollments that have a significant portion of the material that does not change from semester to semester, recorded lectures with Web access [3] is one alternative to repeating the same live lectures.

Introductory circuit courses have been taught several different ways that include interactive software [4], Web-based materials [5], and problem-based learning [6][7][8]. The intention is to depart from the traditional lecturing environment to promote active learning. The flipped classroom is a popular method where professors record lectures and post the video on-line. It is the expectation that students view the lectures before attending class and the time spent in class is used toward working problems or hands-on experiences with peer support and the assistance of an instructor. In a Circuits I flipped course [9][10] 83\% of the students received a grade of " $C$ " or better compared to the previous semester's passing rate of $56 \%$, there was a reduction in standard deviation and student retention was vastly improved.

To complement the recorded lectures, a flipped classroom version of the Elements of Electrical course was offered at the University of Florida for the first time in the spring semester of 2018, although an on-line version had been available for several semesters prior. Students in the flipped classroom attended a weekly two-hour session on campus where they would have access to an instructor to answer questions about material presented in the videos, work problems and offer hands-on learning[11].

To facilitate the hands-on learning, each student was required to purchase an Arduino kit[12]. The students throughout the course of the semester built the circuits described in the kit's tutorials. At the end of the semester, the students were required to complete a project based on the Arduino. As a result, they became acquainted with micro-controller hardware and software, as well as, many different peripherals such as LEDs, switches, temperature measurement, DC motors, piezo speakers, etc. Understanding microcontrollers, an important component of electrical engineering, introduces students to the world of digital control and all the possibilities of enhancing their future disciplines.

\section{Experimental Procedure}

As part of the curriculum at the University of Florida, engineering majors that are not seeking a degree in electrical engineering are required to take a course that broadly covers the different elements of electrical engineering. Because of the number of students that must take this course, the class enrollments can be excessively large. As a result of the high enrollment a single set of core content-recorded lectures have been created and are available to all students through a web portal. Students can choose either the flipped classroom or the on-line only sections. All students watch the same lectures, complete the same assignments (written and hands-on), and take the same exams. The differences are as follows: 
- On-line only - students have access to on-line or live office hours or utilize the online course discussion board for help

- Flipped classroom - students spend time in class with hands-on learning and problem solving with a faculty member. They have access to live office hours and on-line discussion board for help

This work examines the effectiveness of two formats of delivery of the same material. Because both categories of students, "On-line" and "Flipped Classroom", watch the same lectures and complete the same assignments, there is an opportunity to make the comparison.

The data for this came from the fall semester of Elements of the Electrical Engineering course, where 270 engineering students who are not majoring in electrical engineering, learn about circuits, motors, and Op-Amps. The ratio of on-line students to flipped-classroom students is 110 on-line to 160 flipped-classroom. The hands-on aspect consists of building Arduino circuits that are intended to complement the material presented on the videos. Flipped-classroom students build the circuits in the classroom in sections of less than 50 students, with the support of instructors and other students, whereas on-line students work at home, with optional live and on-line office hours and then must record a video of the working circuits and submit it for grading. Both on-line and flipped-classroom students are required to submit a final open-ended design challenge project using their Arduino based circuit kits, which is $10 \%$ of their final grade.

The metrics in this study that compare the on-line and flipped-classroom students are based on the final Arduino project. From the final reports and videos for both categories of students a rubric was designed to rate the complexity, student understanding, and communication of the function of the Arduino-based projects. Students in both categories are also surveyed for selfreported comparison of their comfort level and understanding of the Arduino builds.

In an attempt to quantify differences between the 270 on-line and classroom students, 210 projects were reviewed and assigned two scores on a scale from zero to five where a score of zero is the lowest indicating the student did not deliver a functioning project and five is an exceptional score where the student showed mastery of the material. The two scores were based on the Arduino code and the other for the circuit design. The scores were weighted based on two questions from the survey:

1) What prior level of Arduino builds experience did you have?

a. Essentially No Experience (I have used a hammer and screw driver a few times to assemble furniture, etc. but that's about it)

b. A Little Experience (I have measured/cut/put together/soldered a few build kits or assemblies with a few different hand tools or a power drill or a soldering iron)

c. Mid-Range Experience (I have independently built multiple creations, bought parts/hardware for them on my own, designed portions of the build projects)

d. High-Level of Experience (I have built 20+ functional creations, I have a hobby/slight addiction to making items, I teach others how to make things) 
2) What prior level of programming experience did you have?

a. Essentially No Experience

b. A Little Experience (I took a class on it previously, but have not used it much other than in that class)

c. Mid-Range Experience (programmed a few items independently for fun or internship, etc.)

d. High-Level of Experience (I program for fun and/or profit, my friends come to me for programming help)

For the assignment students were instructed to create, build, program, and document something of their own invention with the Arduino kit using at least 4 of the following components: DC continuous motor, servo motor, LED, buzzer, photo-resistor, potentiometer, push switch, temperature sensor, LCD, and/or Arduino compatible sensors/actuators found commercially available that are different from those already in your kit (air humidity sensor, soil humidity sensor, light strips, solar panels, fans, water pump, etc.).

If the student met this criteria in their build and the circuit functioned as expected, they were given at least the average score of three for both the circuit and the code. Additional points were awarded to the code score if the student wrote their own code instead of modifying existing code from the programs that were included with the Arduino kit. More points were added to the code score when beginning programmers used subroutines or their code showed elegance. If a circuit included a component that was not included in the Arduino kit, e.g. a humidity sensor, the circuit score was increased. Additional points were added to the circuit score if the student connected a circuit in a way that demonstrated a deeper understanding.

\section{Results}

Figure 1 shows the breakdown of the 270 students by year and by major. Mechanical Engineering has the largest enrollment in this course as well as College of Engineering. Because of the prerequisites students generally cannot take this course until their sophomore year and typically wait until their junior year as the data indicates. Enrollment is capped for the on-line section to encourage more students to attend the classroom sections. 

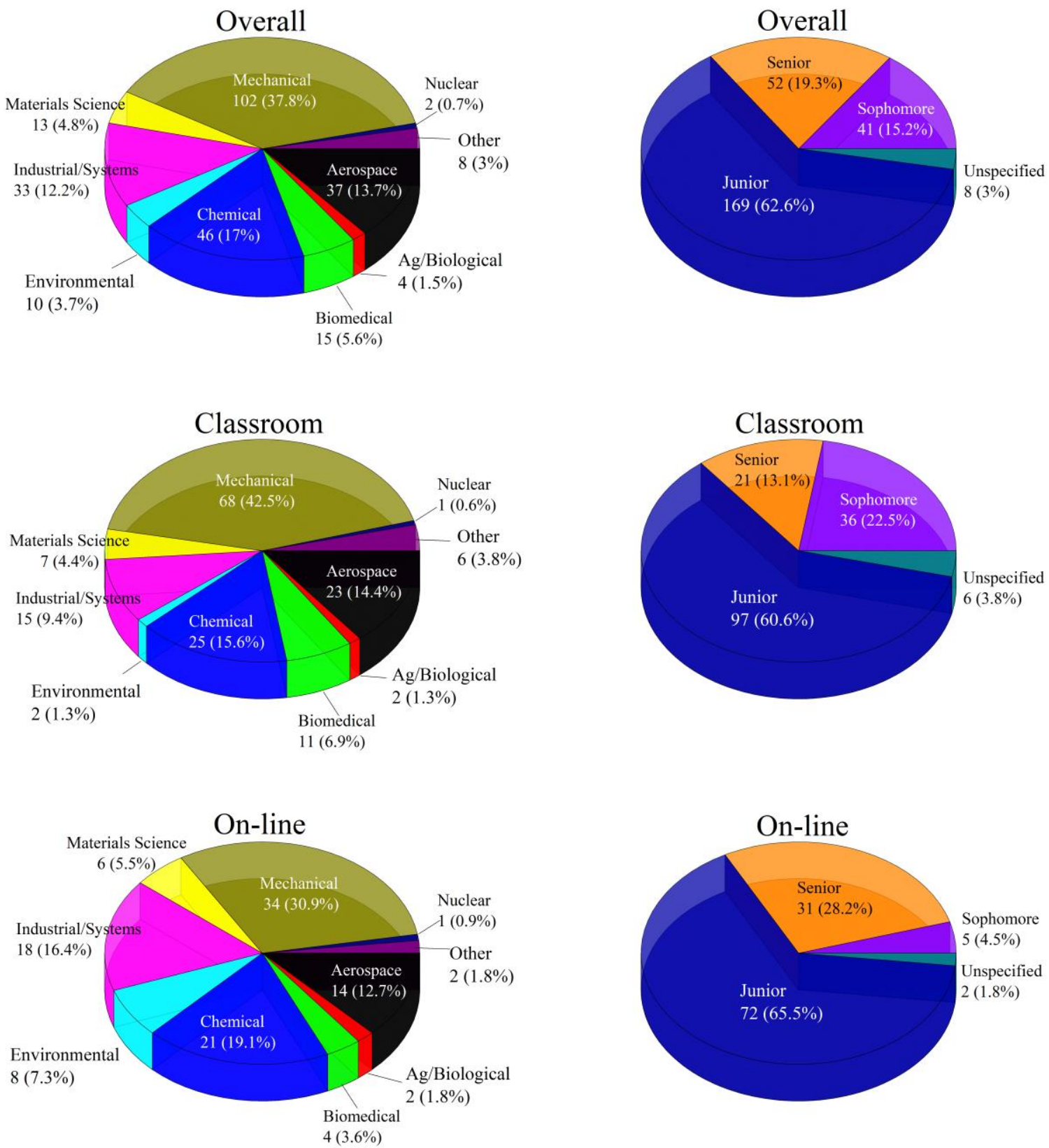

Figure1: Student Enrollment in Elements of Electrical Engineering for the fall 2018 semester.

When surveyed most of the students said they enjoyed the Arduino builds, felt that they complemented the video lectures, and found them to be an important part of the course. Figures 2 and 3 deal with the perception of the actual builds. From Figure 2 students in general experienced very low to moderate anxiety while completing the Arduino builds. Figure 3 suggests that students found the Arduino builds to be relatively simple as the difficulty ranged from moderate to low. 
From Figure 2 students in the classroom appeared to be less anxious while completing the tasks than the on-line students who presumable were working alone and without the immediate assistance of an instructor or the guidance of their peers. Figure 3 is consistent in that on-line students found the Arduino builds to be more difficult than those who completed the tasks in the classroom.

But when it came to their final projects, the students did not stray too far from what they learned in the tutorial builds. Consequently, Figure 4 indicates, the code and circuit scores are very close to the average.

Not all students are included in Figures 4 and 5. Forty-two students failed to create a unique project, but copied another Arduino project from the many available on-line. These projects were not included because they were the equivalent to what the students had been doing all semester, building an existing design and downloading existing code. In addition, eight students did not complete the assignment, seven projects did not work, and three students did not complete the survey.

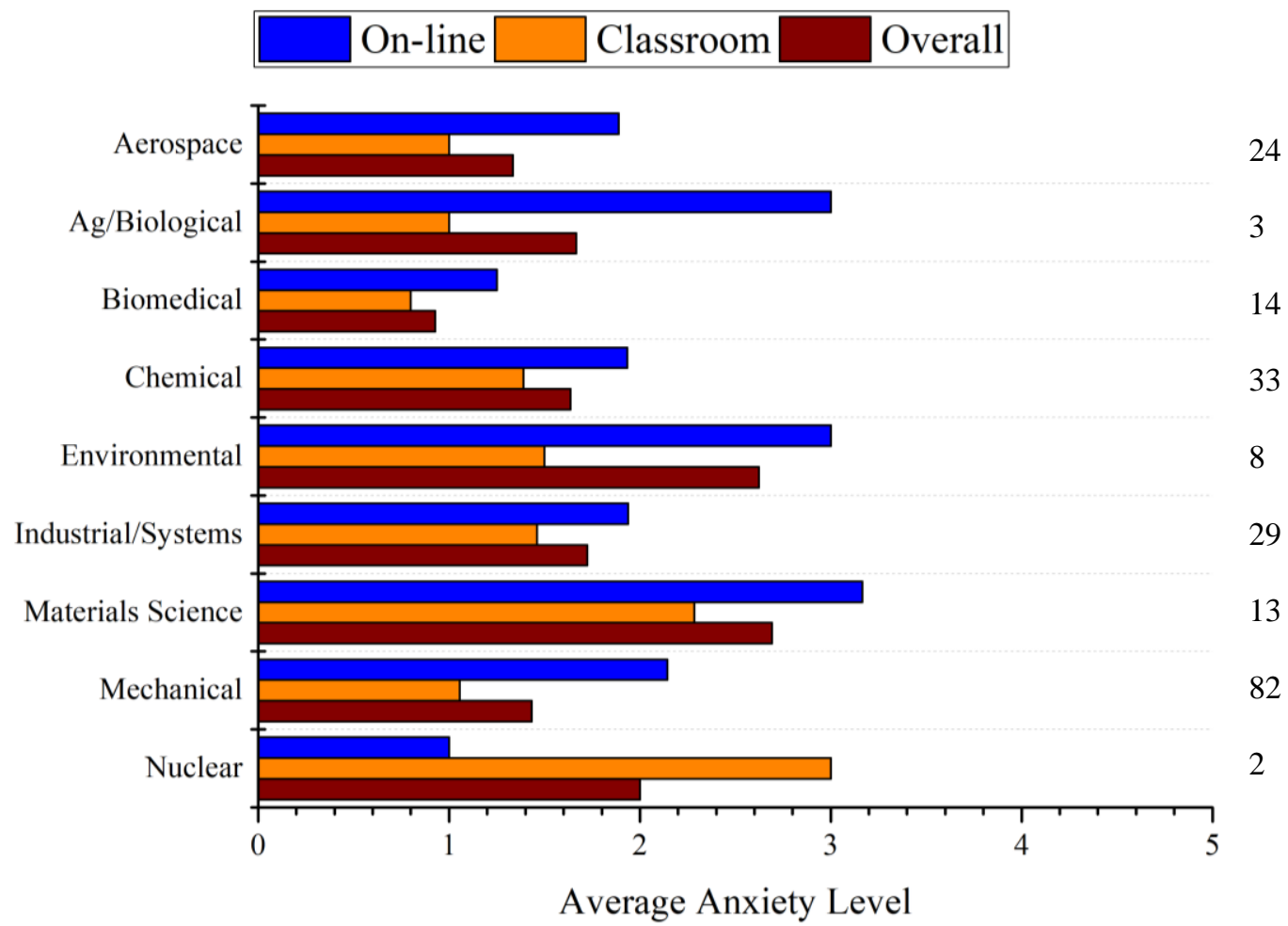

Figure 2: Student responses to the survey question, "Anxiety level while working on the Arduino builds" on a Likert 1-5 scale. The numbers on the left are the number of students for each major. 


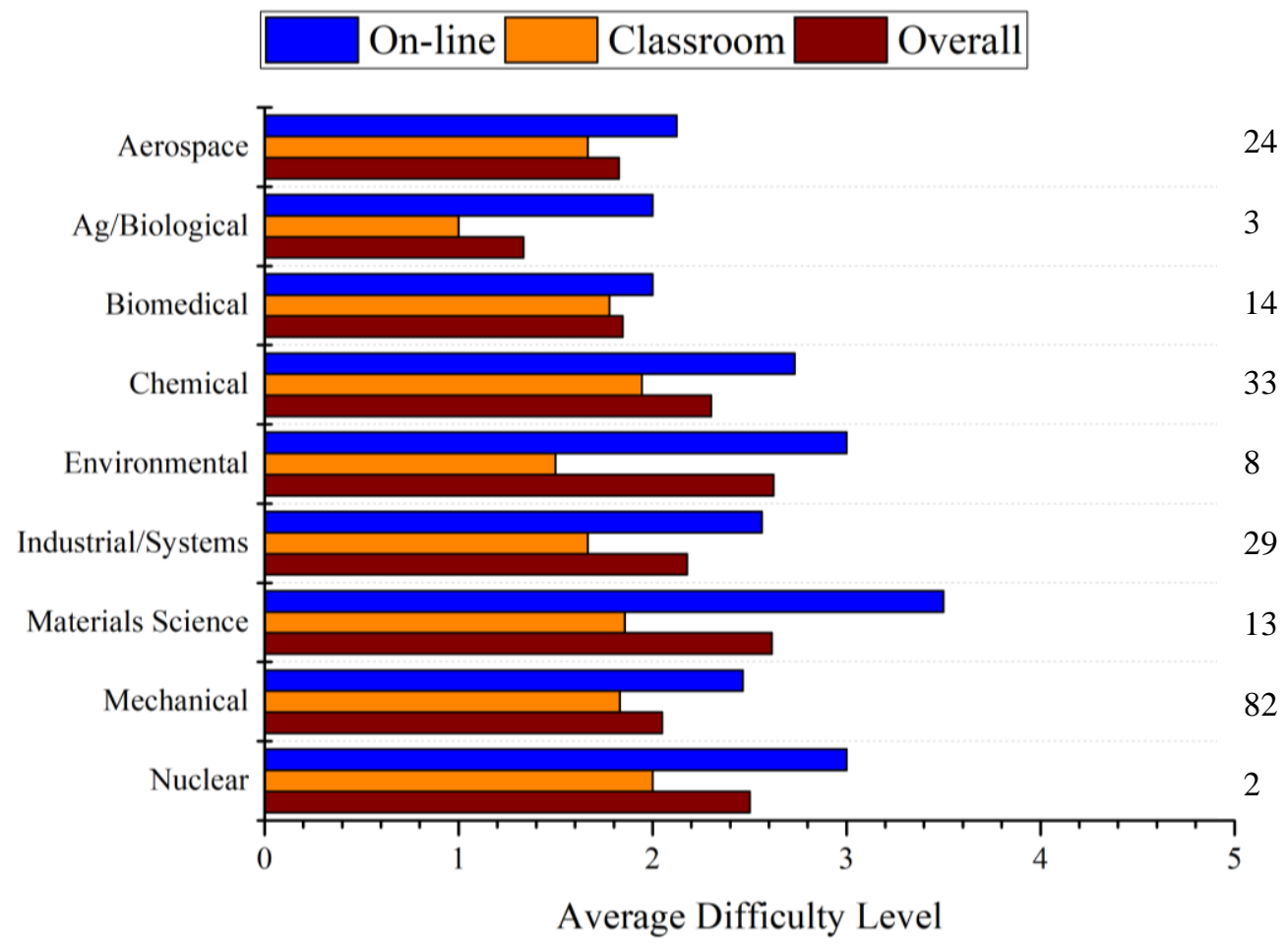

Average Difficulty Level

Figure 3: Student responses to the survey question, "Perceived difficulty of completing the Arduino builds" on a Likert 1-5 scale. The numbers on the left are the number of students for each major.

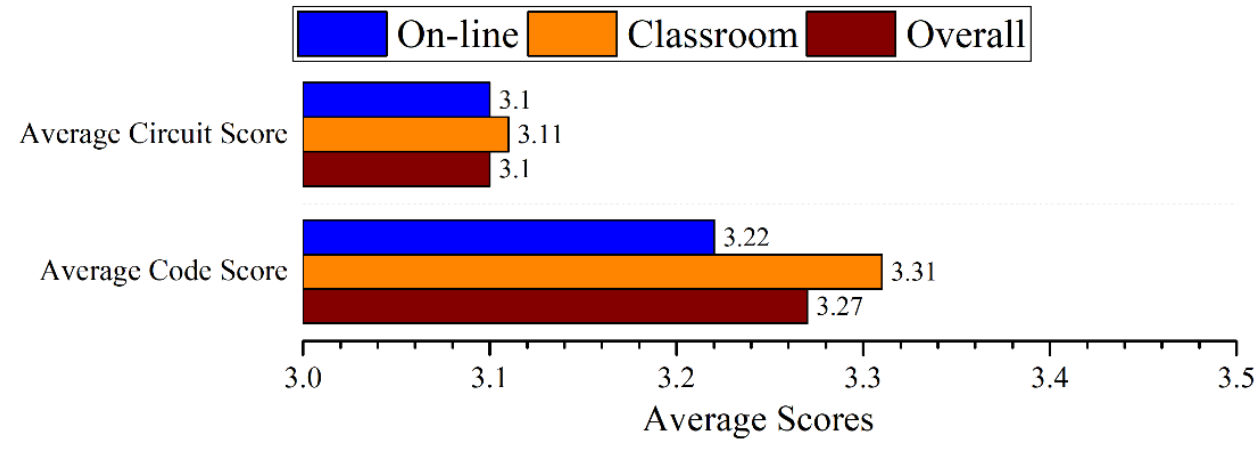

Figure 4: Average code and circuit scores for the fall 2018 Elements of Electrical Engineering course. The overall enrollment was 210 with 87 on-line and 123 classroom students.

Figure 5 shows how the students scored in their respective engineering departments. It is difficult to quantify the smaller department scores, because one outstanding student has a significant impact on the results. For example, an Ag/Biological student created an exceptional project that sorted different colored balls, which skewed the overall score for three students. By focusing on the larger departments with populations of more than ten, the students seemed to perform marginally better than their on-line colleagues in their code scores:

- Chemical Engineering improved by $6.4 \%$

- Industrial by $4.2 \%$

- Material Science by $3.6 \%$

- Mechanical by $4.4 \%$ 
Biomedical is about the same for either case. Aerospace is the outlier with the on-line students performing $4.2 \%$ better than the students in the classroom sections.

Looking at the same departments when considering the circuit score, there appears to be little difference between on-line students and the classroom students.
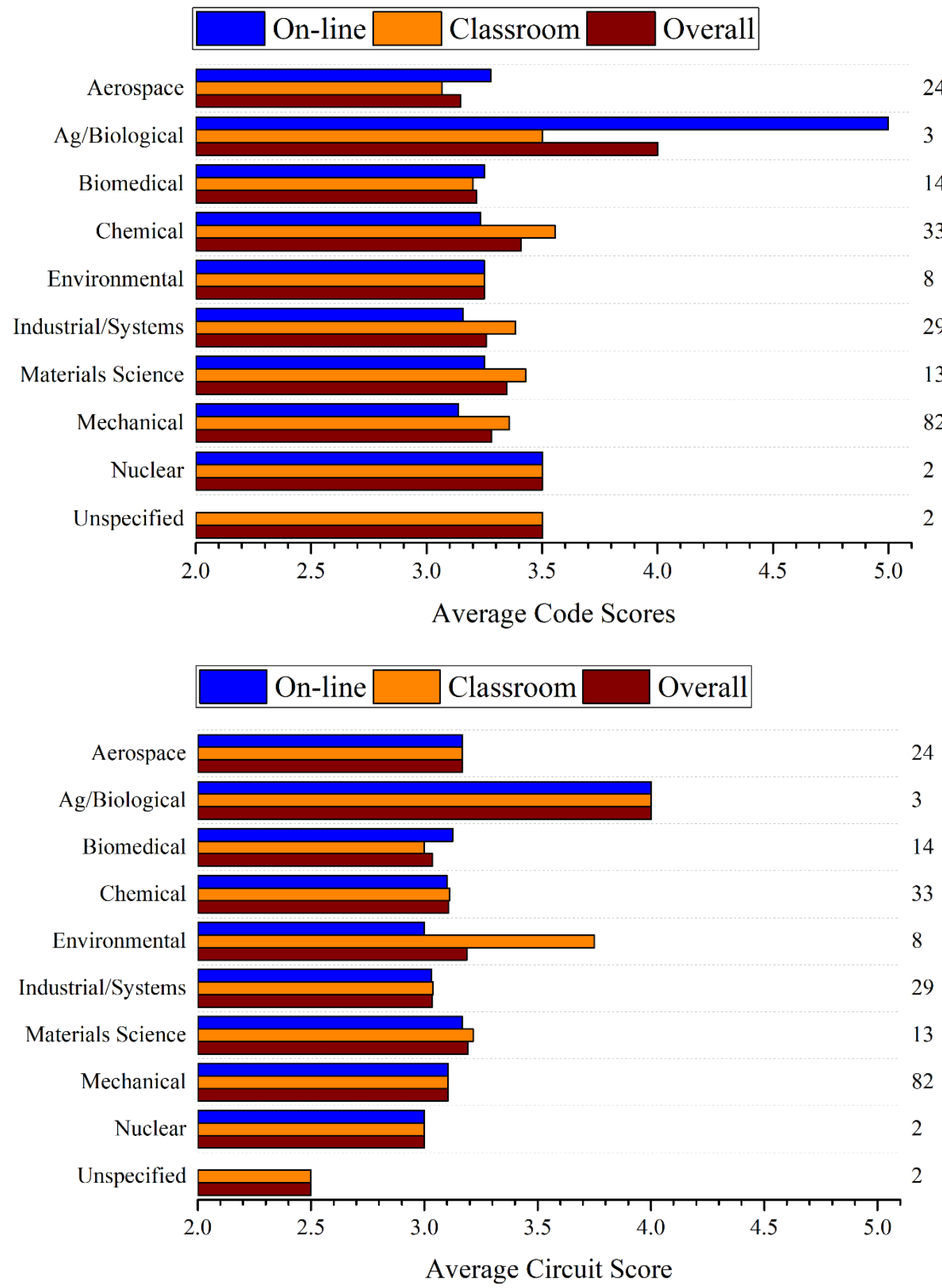

Figure 5: Results by major. The numbers on the left are the number of students for each major. 


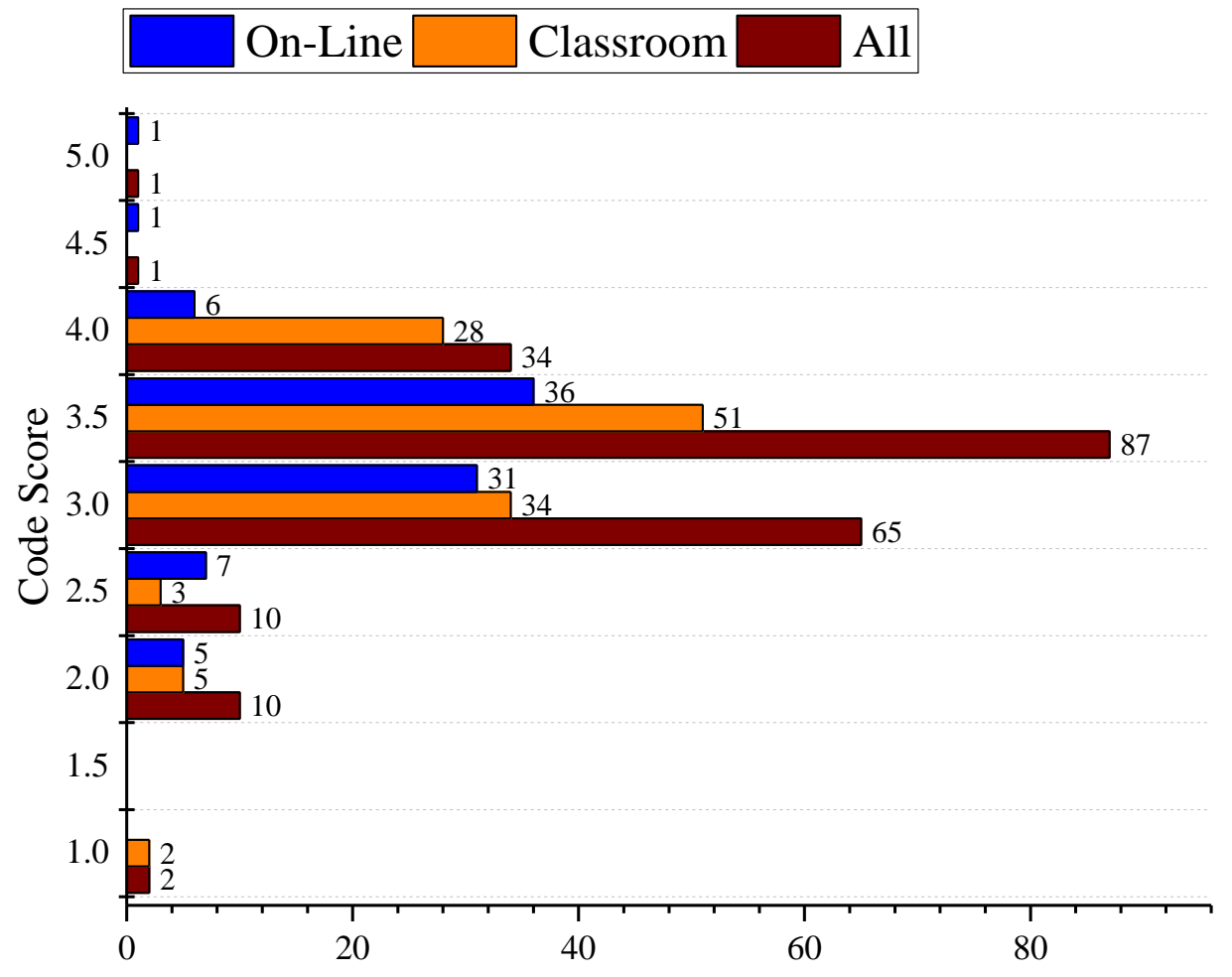

Number of Students

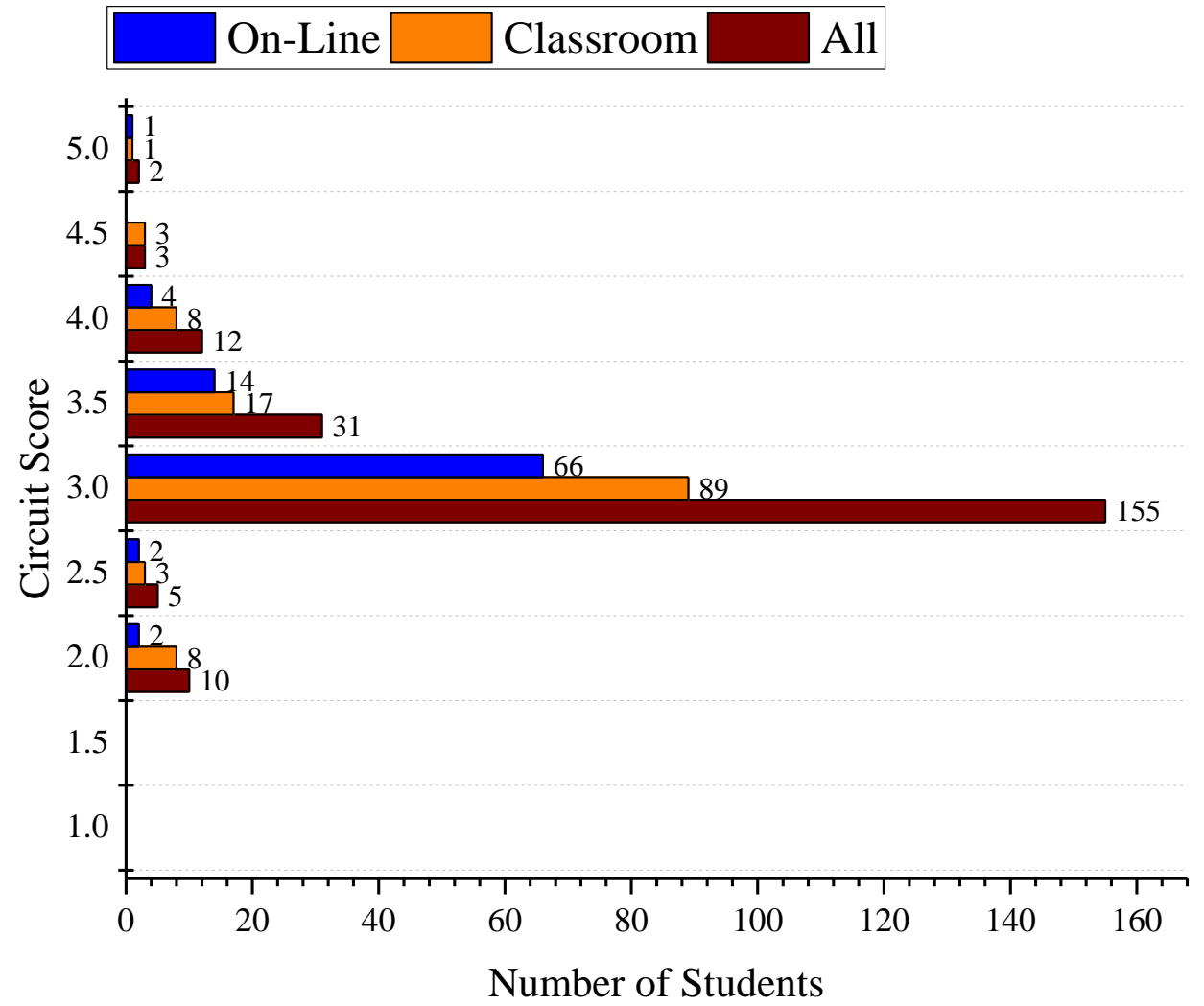

Figure 6: Grade distributions of code scores (top chart) and circuit scores (bottom chart) 
Figure 6 shows most of the students wrote the majority of the code for their projects indicated by the number of students who scored 3.5 or higher. Students who scored 3.0 made minor adjustment to prewritten code mostly from the tutorials. Students who self-reported in the survey as an experienced programmer and wrote minimal code or made slight modifications to prewritten code, received a score less than three.

\section{Discussion and Observations}

In the attempt to quantify the performance of students between the two populations, the data do not appear to definitively determine if one delivery method is superior to the other from this particular experiment, measuring code and circuits of an Arduino-based projects. The expectation was for students who attended the on-campus flipped class to show a marked improvement in their understanding of the material presented in the videos and apply it in the Arduino projects. Although the classroom students scored marginally higher, perhaps the Arduino project may not be best metric for comprehension and application. Consequently, no further statistical analysis was done on the data. Instead the focus is on the experiment itself and how it may be conducted differently. By observation, there does not appear to be any statistical significance between the two populations. Speculations as to why this is the case include the following reasons:

- The material that is presented in the video lectures does not always support but tends to compliment the learning that comes from the Arduino tutorial and project. A student could easily be a very strong builder of Arduino circuits but not fully grasp the material presented in the videos. Therefore, another metric could be considered to measure the differences between the two populations.

- The tutorials that come with the Arduino kit are thorough and very accessible to anyone with a technical inclination. The circuits are given to the user and the code is prewritten and downloaded from the integrated development environment. If the student can duplicate the wiring from a picture of a breadboard circuit, they can easily complete the builds. As part of the homework assignments students must turn-in a flowchart of the code, forcing students to consider how the Arduino circuit functions. As stated in the previous bullet point, the Arduino may not be the best metric.

- Motivating students to go beyond the assignment's minimum requirement is challenging.

- Many students who self-reported themselves as novice programmers with no Arduino experience, wrote their own code and experimented with peripherals not covered in the tutorials. This is evidenced in the number of above average scores (3.5) in Figure 6. Alternatively, the students who self-report themselves as experienced programmers, did not apply their abilities and wrote very simple code (scores below average).

- The circuit scores stayed very close to average because most students replicated circuits from the tutorials. There could be various reasons for this, such as not having the financial means to purchase items not in the kit, or the students simply not knowing what is available to them.

- When comparing this course to a capstone design class, bragging-rights and prize competitions tend to be excellent motivators.

- Because enrollment is capped in the on-line sections, not all students are able to selfselect if the flipped classroom is their best option. Since seniors register before 
sophomores, the underclassman may only have the flipped classroom as an option. Therefore, it is difficult to determine if the students who would have most benefitted from the classroom environment had that as an option or if they are self-aware to choose what is best for them.

One interesting observation from the data, specifically Figures 2 and 3, suggest the classroom students found the Arduino builds to be less stressful and not as difficult when comparted to the on-line students. The classroom students could get immediate assistance from the instructor and could consult classmates during the build process.

\section{Summary and Conclusions}

In order to determine if adding a weekly flipped-classroom session to on-line videos provides a more comprehensive education, a quantitative attempt was made using the final class project as the focus. The results show the students who attended the flipped session had marginally better projects according to the scoring rubric used, but nothing significant. Reasons for the lack of anything conclusive might be due to how the metric was used in the experiment and student motivation. Further study is needed to develop a more in-depth experiment. Future work include repeating the study, but providing more incentives to motivate the students. Incentives could include a competition for best projects. Our current plan is to offer extra credit toward the final grade if students add more components, increase complexity in their circuitry, or focus on writing their own code.

When the students were surveyed, $79 \%$ of the students say they enjoyed the instructional methods used in the course and $82 \%$ of the students were engaged by the instructional methods used. Overall, the survey response overwhelmingly shows that students like the addition of the Arduino tutorials and find them to be useful. Additionally, the Arduino lessons broaden the scope of the course by including digital design and system integration.

\section{References}

[1] A. Karabulut-Ilgu, N. Jaramillo Cherrez, and C. T. Jahren, "A systematic review of research on the flipped learning method in engineering education," Br. J. Educ. Technol., vol. 49, no. 3, pp. 398-411, 2018.

[2] J. L. Bishop and M. A. Verleger, "The Flipped Classroom : A Survey of the Research The Flipped Classrom," Proccedings Annu. Conf. Am. Soc. Eng. Educ., p. 23.1200.123.1200.18, 2013.

[3] J. Bourne, D. Harris, and F. Mayadas, "Online Engineering Education: Learning Anywhere, Anytime,” J. Eng. Educ., vol. 94, no. 1, pp. 131-146, 2013.

[4] I. Oakley, B., "A virtual classroom approach to teaching circuit analysis," IEEE Trans. Educ., vol. 39, no. 3, pp. 287-296, 1996.

[5] L. Palma, R. F. Morrison, P. N. Enjeti, and J. W. Howze, "Use of web-based materials to teach electric circuit theory," IEEE Trans. Educ., vol. 48, no. 4, pp. 729-734, 2005. 
[6] L. R. J. Costa, M. Honkala, and A. Lehtovuori, "Applying the problem-based learning approach to teach elementary circuit analysis," IEEE Trans. Educ., vol. 50, no. 1, pp. 4148, 2007.

[7] M. A. L. U. \& C. F. B. Yadav, A., Dipendra Subedi, "Problembased Learning: Influence on Students' Learning in an Electrical Engineering Course. Journal of Engineering Education 100(2):253-280," vol. 100, no. 2, pp. 253-280, 2011.

[8] J. P. Becker, C. Plumb, and R. A. Revia, "Project circuits in a basic electric circuits course," IEEE Trans. Educ., vol. 57, no. 2, pp. 75-82, 2014.

[9] G. J. Kim, E. E. Patrick, R. Srivastava, and M. E. Law, "Perspective on flipping Circuits i," IEEE Trans. Educ., vol. 57, no. 3, pp. 188-192, 2014.

[10] B. Kerr, "The flipped classroom in engineering education: A survey of the research," Proc. 2015 Int. Conf. Interact. Collab. Learn. ICL 2015, no. September, pp. 815-818, 2015.

[11] A. Gero, "Increasing Motivation of Engineering Students : Combining "“ Real World " Examples in a Basic Electric Circuits Course *," Int. J. Eng. Educ., vol. 32, no. 6, pp. 2460-2469, 2016.

[12] “Arduino Starter Kit.” [Online]. Available: https://store.arduino.cc/usa/arduino-starter-kit. 